\title{
Australian Journal of \\ Effect of biochar and inoculation with Trichoderma aureoviride on melon growth and sandy Entisol quality
}

\author{
Erika Valente de Medeiros ${ }^{1 *}$, Marcele de Cássia Henriques dos Santos Moraes ${ }^{1}$, Diogo Paes da Costa ${ }^{1}$, \\ Gustavo Pereira Duda ${ }^{1}$, Julyana Braga de Oliveira ${ }^{1}$,Jenifer Sthephanie Araujo da Silva ${ }^{1}$, José Romualdo de \\ Sousa Lima ${ }^{1}$, Claude Hammecker ${ }^{2}$
}

\author{
${ }^{1}$ Laboratory of Microbiology, Federal Rural University of Pernambuco, Garanhuns, PE, Brazil \\ ${ }^{2}$ IRD/UMR Eco \& Sol, place Pierre Viala, 2, 34060 Montpellier, France
}

\section{*Corresponding author: evmbio@gmail.com; marcele-moraes@hotmail.com}

\begin{abstract}
The melon belongs to the family of commercially important cucurbitaceous in the world. However, the production of this crop can be very problematic in some places due to management practices and the climatic instability. Amongst the different options available to overcome these obstacles, the use of biochar often promoted for providing multiple benefits to crops, could contribute in holding more water and nutrients in soil and therefore improve the plant growth. A second way to try to improve the plant development was to use Trichoderma (TRI) known as aiding in seed germination, and being an excellent biological control agent against plant pathogenic pests. So, the objective of this study was to evaluate the benefits of the association of biochar and TRI on the initial growth of melon and the effects on the quality of a sandy Entisol. We quantified the effects of these associations through biometric growth in melon plants and chemical, microbial, and enzymatic activities of the biogeochemical cycles in the soil. An experiment in a completely of randomized design was performed in a factorial scheme $(3 \times 2+1)$ with three sources of biochar (bean husk (BH), coffee ground (CG), and coffee husk $(\mathrm{CH})$ ) inoculated with $(\mathrm{T}+$ ) or without $(\mathrm{T}-$ ) $\mathrm{TRI}$ and additional controls When the coffee grounds (CG) and bean husks (BH) biochar with $\mathrm{T}+$ soil was inoculated, the fresh weight (number of leaves), dry weight, length (of roots and branch), soil acid and alkaline phosphatase, total organic carbon, phosphorus, magnesium, potassium, and pH were all increased. Moreover, T. aureoviride inoculated CG biochar compared to the control increased the shoot length and dry biomass of the melon plant in 30 and $22 \%$ between 22 and $30 \%$. The soil that received coffee husks $(\mathrm{CH})$ biochar and $\mathrm{T}+$ showed higher microbial biomass carbon. However, the melon plants responded more to the type of biochar than to the T. aureoviride inoculation, possibly due to the short growth time of melon. Results of BH biochar inoculated with T. aureviride in sandy soil showed improved efficiency on melon growth and increased soil quality.
\end{abstract}

Keywords: Biocarbon; Cycling of nutrients, Plant growth; Route of inoculation; Soil fertility.

Abbreviations : $\mathrm{CG}$ _coffee grounds; $\mathrm{CH}$ _coffee husks; $\mathrm{BH} \_$bean husks; $+\mathrm{T}$ _with inoculation of Trichoderma aureoviride; $-\mathrm{T}$-without inoculation of Trichoderma aureoviride; RDB_root dry biomass; RFB_root fresh biomass; SDB_shoot dry biomass; SFB_shoot fresh biomass; SLEN_shoot length; RLEN_root length; DIA_diameter; NL_number of leaves; ChloA_Chlorophyll a; CholB_Chlorophyll b; Ure_soil Urease; Bet_ß-glycosidase; P.Alc_alkaline phosphatase; P.Aci_acid phosphatase; TOC_total organic carbon; MBC_microbial biomass carbon; SBR_soil basal respiration; qCO2_soil metabolic quotient.

Introduction

Melon (Cucumis melo L.) is one of the most important species of the Cucurbitaceae family, which is cultivated worldwide, because its pulp is refreshing with a high nutritional value and pleasant aroma, besides having an extensive range of medicinal properties (Mallek-Ayadi et al., 2018). Melon production is carried out in semi-arid regions with excessive use of agricultural inputs, especially synthetic fertilizers and water for irrigation (Deus et al., 2015). The high costs of fertilizers have triggered the development of alternative products able to fulfil partial, or total nutrient demand of the crop.

In this sense, studies have shown that biochar was an alternative agricultural input for crops, being a low-cost, nutrient-concentrated product obtained through the pyrolysis of different biomasses, including agro-industrial residues, under limited oxygen $\left(\mathrm{O}_{2}\right)$ conditions (Lima et al., 2018; Yang et al., 2018). Biochar application to soil mitigates the emission of gases, increases $C$ sequestration, and improves the structure, fertility, activity of beneficial microorganisms, soil water retention, and agricultural productivity (Weber and Quicker, 2018). Biochar is a soil conditioner that can promote plant growth by improving retention of nutrients and soil fertility but also soil physical attributes, like density and soil water retention (Paneque et al. 2016). It can also modify the composition and abundance of the soil biological community. These changes may also alter nutrient cycling (Anyanwu et al., 2018).

Biochar was successfully used as an inoculation vehicle of microorganisms beneficial to the soil and plants (Medeiros et al. 2019). In this sense, Trichoderma spp. is essential for 
its versatility in promoting plant development and controlling soil pathogens (Swain et al., 2018). These fungi are mycoparasites secreting secondary metabolites, phytohormones, and enzymes known for assisting root growth and controling viruses, pathogenic bacteria, and insect pests (Mendoza-Mendoza et al., 2018).

This study raised the hypothesis that biochar could be a potential vehicle for inoculation of Trichoderma spp., improving several soil attributes that increase the initial development of melon. As little information about this subject was available, the objective of the present study was to evaluate the effects of biochar from different sources with and without $T$. aureoviride applied to sandy Entisol on the initial melon plant growth and to assess the changes in chemical, microbiological, and enzyme activities regarding the soil attributes.

\section{Results}

\section{Beneficial effects of the inoculation of T. aureoviride via biochar on initial melon growth and soil quality}

Non-metric multidimensional scaling (nMDS) showed that the variations in melon plants responded more to the type of applied biochar (higher separation between points) than to the presence or absence of $T$. aureoviride (closest; Fig. 1). Each type of biochar generated a distinct soil biochemical pattern, primarily due to changes in $\mathrm{pH}, \beta$-glucosidase, and urease activities and the $\mathrm{Mg}^{2+}, \mathrm{K}^{+}$and $\mathrm{P}$ levels in the soil, which was the most sensitive variables in the applied treatments.

However, the inoculation of $T$. aureoviride revealed significant increases of plant development with responses being modulated as a function of the biochar type. For example the treatment with inoculated coffee husks biochar $(\mathrm{CH}+\mathrm{T})$ was different from all other treatments (Fig. 1). This treatment showed a high increase in soil pH $(\sim 7.0), \mathrm{Ca}^{2+}, \mathrm{K}^{+}$, and $\mathrm{MBC}$ levels, being significantly higher than in other biochar sources (Table 1).

\section{Analysis of variance (ANOVA) and comparisons between averages}

Coffee ground biochar with $T$. aureoviride $(C G+T)$ applied to the sandy soil cultivated with melon showed an increase in $\beta$-glucosidase activity, while for the others the $\beta$-glucosidase activity was, reduced compared to the control (Table 1 ). The most significant improvements with this treatment were for $R D B, R F B, S D B$, and $S F B$, showing a higher potential for promoting plant development. Bean husks with $T$. aureoviride $(\mathrm{BH}+\mathrm{T})$ applied to the soil showed a significant increase in RLEN (Table 1).

\section{Interactions between analyzed variables}

Some soil metabolic and chemical variables showed significant correlations with the biometric variables of melon plants. Among these, $\beta$-glucosidase activity showed a positive correlations with the diameter of the main branch and $R F B, S F B$, and, $S D B$ (Fig. 2A). Urease activity was positively correlated with the shoot fresh matter and showed negative correlations with the shoot length and with the content of Chlorophyll $b$.

The melon shoots were longer in soil with higher $\mathrm{P}$ and $\mathrm{Mg}^{2+}$ levels, as illustrated by the positive correlations between shoot length versus $\mathrm{P}$ and $\mathrm{Mg}$ concentration in soil (Fig. 2B).
We found other positive and significant relationships between the contents of $\mathrm{H}^{+}+\mathrm{Al}^{3+}$ with diameter, root length, root fresh matter, and shoot fresh and dry matter.

Regarding the interactions between soil metabolic and chemical attributes (Fig. 2C), some strong positive and significant relationships were observed, highlighting correlations: (i) between total organic carbon and soil $\mathrm{Mg}^{2+}$ and $\mathrm{P}$ contents; (ii) between urease activity and $\mathrm{Ca}^{2+}$; (iii) between acid phosphatase activity and soil $\mathrm{P}$ content.

\section{Discussion}

Application of biochar to the soil provides numerous improvements, such as increasing fertility, promoting aggregates formation, and increasing carbon stock (Yang et al., 2018). In the present study, each type of biochar showed different chemical composition, microbial activity, and enzymatic expression (Fig. 1 and Table 1).

Soil $\mathrm{pH}$ was one of the most affected parameter by biochar addition especially when soil had been amended with $\mathrm{CH}$. This was mainly attributed to negatively charged chemical groups on the biochar surfaces (Lima et al., 2018), such as carboxylic, phenolic, and hydroxylic radicals, as well as silicates, carbonates, and bicarbonates that bind to $\mathrm{H}^{+}$ions, making the $\mathrm{pH}$ of the soil more alkaline (Gul et al., 2015).

One of the main advantages of increasing $\mathrm{pH}$ in tropical soils is the increase in $\mathrm{P}$ availability for plants, mainly as monoand di-calcium phosphate, which are most soluble for an optimum pH ranging between 6.0 and 7.0 (Buss et al., 2018). In this case, the effect of adequate soil $\mathrm{pH}$ for bean husk biochar amendments, probably contributed to the higher levels of $P$ for this biochar (Table 1 ). These results are analogous to those of Born $\varnothing$ et al. (2018) demonstrating that the type of biochar influenced the adsorption and bioavailability of $\mathrm{P}$ when added to $\mathrm{Ca}^{2+}, \mathrm{Mg}^{2+}$, and $\mathrm{K}^{+}$oxides rich soil.

The simultaneous increase of $\mathrm{pH}$ and carbonate availability with biochar amendment favored the formation of organomineral complexes that stimulated microbial activity and promoted soil organic carbon stability (Sheng and Zhu, 2018). Results obtained in the present study corroborated these findings since the soils with $\mathrm{CH}+\mathrm{T}$ and a $\mathrm{pH}$ of 7.0 showed a significant increase of the MBC. These results also revealed the active participation of $T$. aureoviride in this treatment, as the optimal conditions where reached for this fungus to increase the MBC of the soil significantly.

The soil amended with CG and $T$. aureoviride (CG + T) displayed active participation of $T$. aureoviride in carbon cycling as this treatment has significantly increased the activity of $\beta$-glycosidases, enzymes produced by microorganisms degrading cellulose and other carbohydrates present in the cell walls (Strahsburger et al., 2017). Similarly, Wu et al. (2018) demonstrated that the addition of biochar substantially increased the activity of $\beta$-glycosidase, but also cellobiohydrolase, and chitinases in sandy soils, especially in an acidic pH. Different soils showed similar effects. For example, Teutscherova et al. (2018), in the various Mediterranean regions, verified that acidic soils treated with biochar showed higher responses through increased activities of dehydrogenase, urease, $\mathrm{pH}, \mathrm{MBC}$, and $S B R$ during the initial six weeks of incubation.

The increase of RFM and SFM of melon plants, promoted by the association between CG and T. aureoviride obtained in the present study, showed that the benefits of this fungus for the plants was strictly related to the use of a suitable substrate. Galletti et al. (2015) demonstrated that the 
inoculation of Trichoderma harzianum in melon seeds promoted the increase of microbial biomass and nutrient cycling in the soil, resulting in a significant increase in dry matter and the root length of melon plants. Root elongation directly reflects the overall development of the entire plant (Prasad et al., 2018). However, in the study of Galletti et al.,

Table 1. Enzymatic/metabolic attributes of carbon (A), soil chemicals (B), and biometrics of plants (C) treated with different biochars from coffee grounds $(\mathrm{CG})$, coffee husks $(\mathrm{CH})$, and bean husks $(\mathrm{BH})$ with $(+\mathrm{T})$ and without $(-\mathrm{T})$ inoculation of Trichoderma aureoviride under cultivation of melon plants of the variety BRS Araguaia.

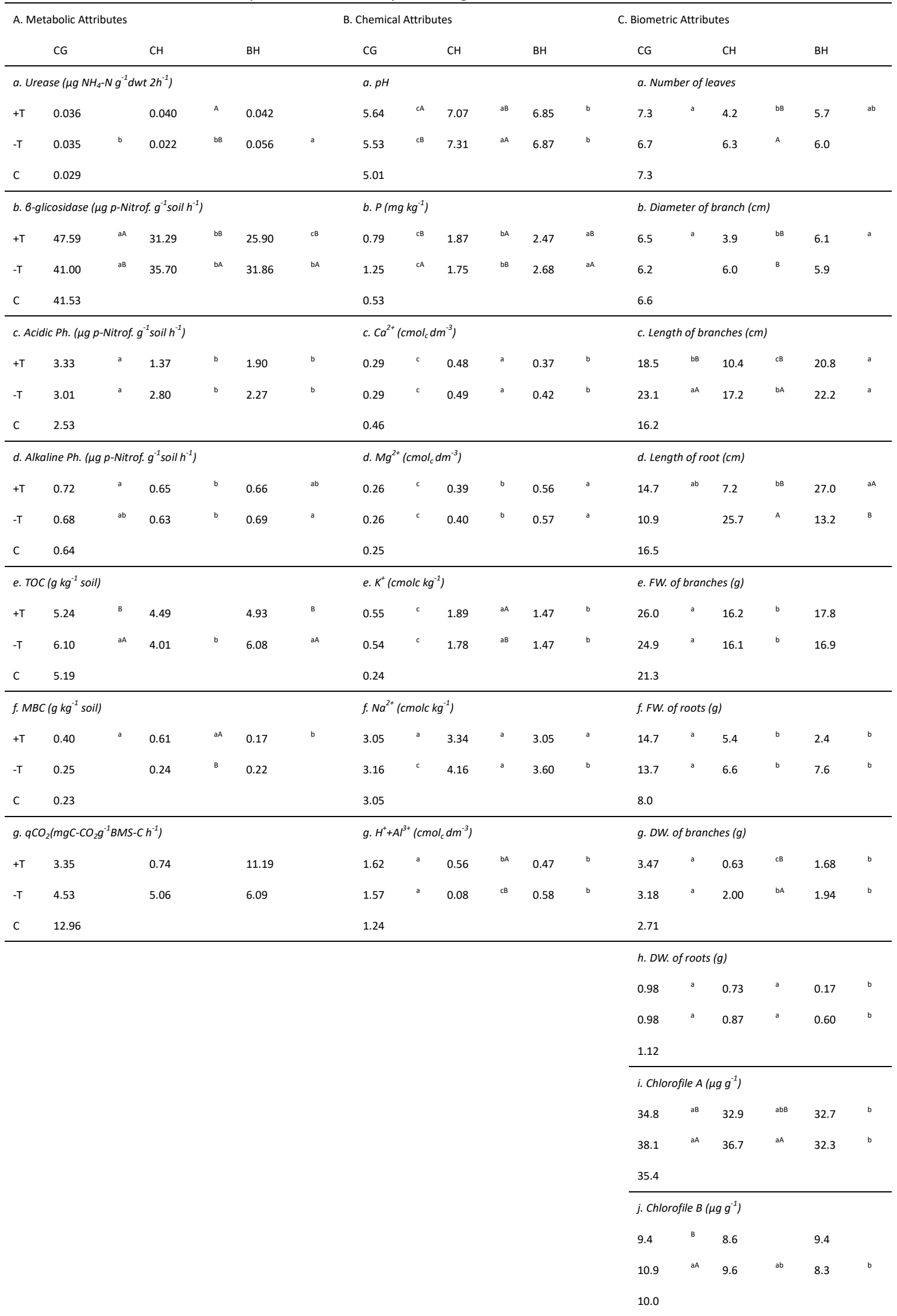




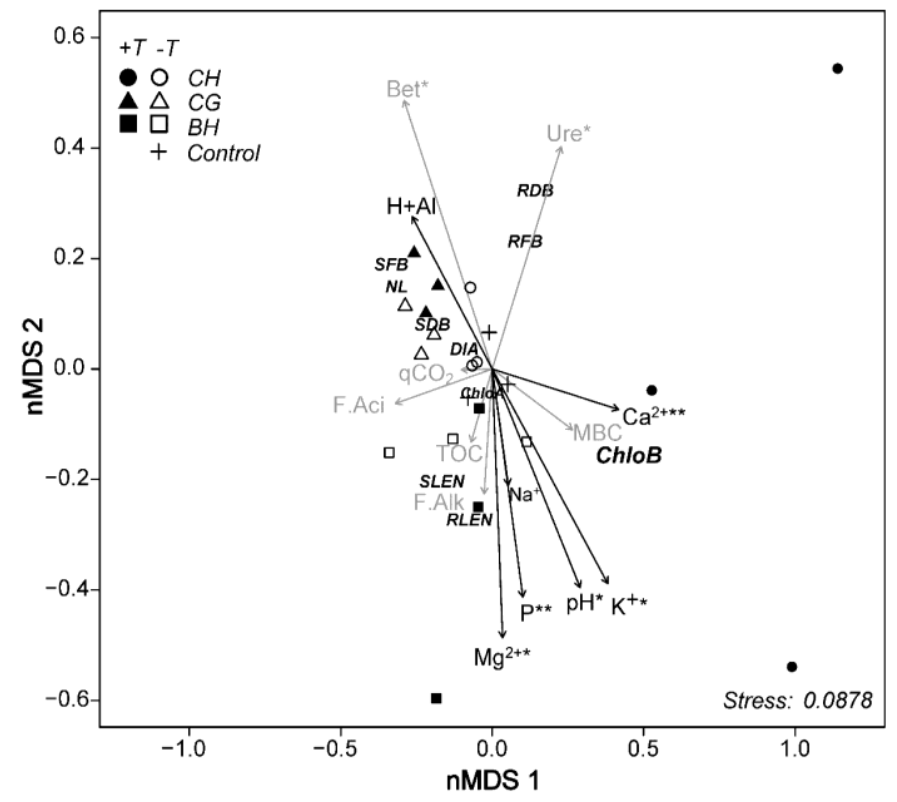

Fig 1. Dissimilarities between the metabolic activities of microorganisms in soils cultivated with melon enriched with biochar from bean husks $(\mathrm{BH})$, coffee grounds $(\mathrm{CG})$, and coffee husks $(\mathrm{CH})$ with $(\mathrm{T}+)$ and without $(\mathrm{T}-)$ T. aureoviride. Non-metric multidimensional scaling (nMDS) revealed a reasonable fit of the explanatory model, according to the stress measure $(\mathrm{Sm}=.087, \mathrm{~K}(\mathrm{dimension})=3$ ) suggested by Kruskal (1964). The vectors corresponding to the chemical (black) and metabolic (in gray) attributes followed by asterisks ( ${ }^{*}$ and ${ }^{* *}$ ) have significant correlations $(\rho \leq .05$ and .10$)$ with the ordering configuration about the axes. Root dry biomass $(R D B)$, root fresh biomass (RFB), shoot dry biomass (SDB), shoot fresh biomass (SFB), shoot length (SLEN), root length (RLEN), diameter (DIA), number of leaves (NL), Chlorophyll a (ChloA), Chlorophyll b (ChloB) of melon plants; soil Urease (Ure), B-glycosidase (Bet), alkaline phosphatase (P.Alc), acid phosphatase (P.Aci) activities, total organic carbon (TOC), microbial biomass carbon (MBC), soil basal respiration (SBR), soil metabolic quotient (qCO2).
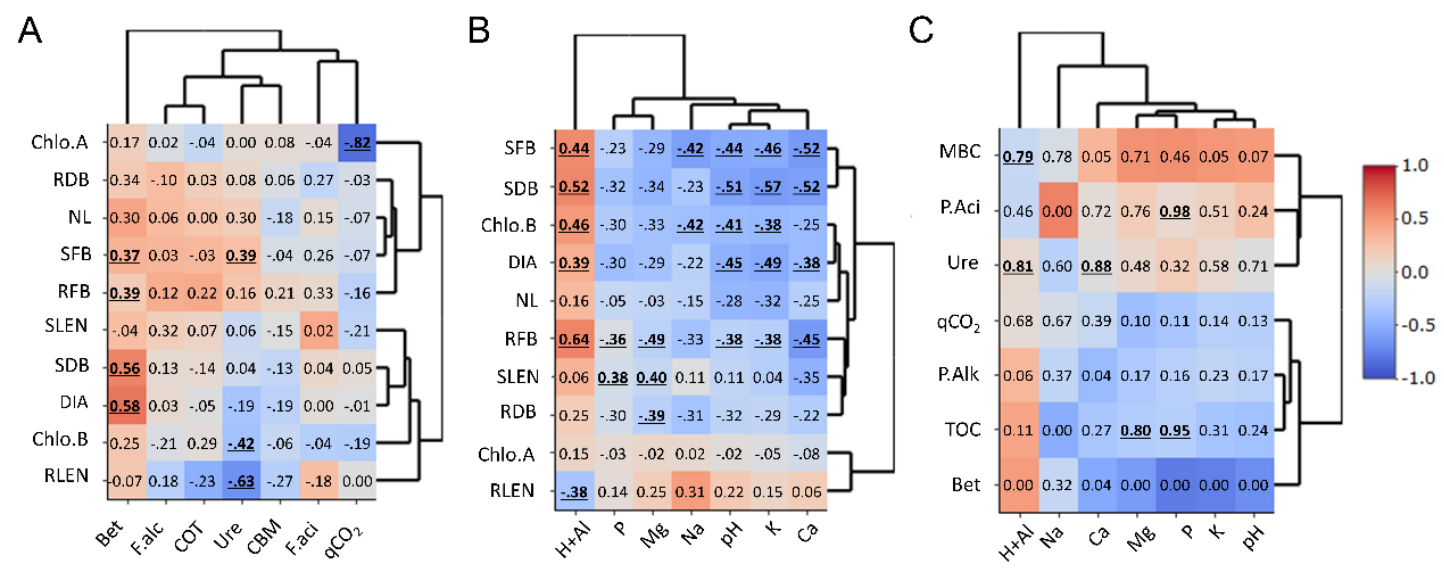

Fig 2. Correlations between biometric data of melon plants, soil enzymatic activities, and chemical attributes on soils with different treatments of biochar with and without Trichoderma aureoviride. The heatmap and Pearson correlation coefficients $(R p)$ station were used to associate the paired samples. The underlined correlations are significant $(\rho \leq .05)$. In general, the Mantel test revealed significant positive correlations between plant biometric and soil metabolic attributes $(\mathbf{A}, r=.39, \rho=.001)$, biometric and chemical attributes (B, $r=.16, \rho=.023)$, and metabolic and chemical $(C, r=.26, \rho=.001)$. Root dry biomass (RDB), root fresh biomass (RFB), shoot dry biomass (SDB), shoot fresh biomass (SFB), shoot length (SLEN), root length (RLEN), diameter (DIA), number of leaves (NL), Chlorophyll a (ChloA), Chlorophyll b (ChloB) of melon plants; soil Urease (Ure), 6-glycosidase (Bet), alkaline phosphatase (P.Alc), acid phosphatase (P.Aci) activities, total organic carbon (TOC), microbial biomass carbon (MBC), soil basal respiration (SBR), soil metabolic quotient (qCO2).

(2015), Trichoderma did not affect significantly the activities of $\beta$-glucosidase, unlike in the present study.

In this context, enzymatic activity of $\beta$-glycosidase correlated strongly with the main biometric attributes of the melon: $D I A M, R F B, S F B$, and $S D B$ (Fig. 2A). It showed a strong relation between these variables and the CG biochar with T. aureoviride. This treatment provided general improvements in the soil since $\beta$-glucosidase, urease and phosphatase soil activities are efficient indicators of soil quality (Adetunji et al., 2017). In these conditions, it is also worth mentioning the significant positive correlations between urease and the SFM plants (Fig. 2B) and between phosphatase and labile $\mathrm{P}$ in the soil (Fig. 2C). 
Among the main functions of $\beta$-glucosidase and soil urease, the equilibrium of the $\mathrm{C}: \mathrm{N}$ ratio was also representative of the metabolic activity. In a previous study using the same substrates, they acquired the $\mathrm{C}: \mathrm{N}$ ratio of 32.73 for the biochar of $\mathrm{CH}$ and 16 for the biochar of CG (Lima et al., 2018). Song et al. (2018) studied the metabolic activity of soils treated with maize straw biochar and found that $\mathrm{C}$ : $\mathrm{N}$ ratio, $\mathrm{K}^{+}$and $\mathrm{MBC}$ content were the dominant factors affecting soil microbial community. These authors also found that biochar amendements with formulated NPK fertilizer, as adopted in the present study, favoured fast-growing bacteria (r-strategists) on fungi. In this case, $\mathrm{N}$ mineralization of organic matter occurred to compensate for the high C: $\mathrm{N}$ ratios after the addition of biochar.

In this context, as different types biochar contribute distinctly towards the metabolic activity of soils, the addition of alternative mineral sources may also influence the behavior of soil microorganisms differently. This result is due to the different nutritional needs of each microbial taxon, and this difference is even higher among fungi and bacteria, for which the optimal C: N ratios are 8.3 and 4.4 , respectively (Mouginot et al., 2014).

Moreover, biochar does not only serve as an inoculation pathway for Trichoderma spp. but also serves as a substrate for inoculation of different microorganisms. For example, in the study conducted by Tripti et al. (2017), tomato plants inoculated with strains of Bacillus sp. and Burkholderia sp. via biochar showed significant increases of dry and fresh biomass, plant length, and the number of flowers. An increase of dehydrogenase activity and soil fertility was also recorded, leading to a significative tomato productivity increase and therefore replacing high-cost mineral fertilizers. These data reinforce the need to better explore biochar as a new alternative for managing green manure fertilization especially considering the rising prices and the scarcity of mineral fertilizers.

Positive and significant correlation of soil chemical attributes with the biometric variables, highlight the positive relations between the shoot length of melon plants with the contents of $\mathrm{P}$ and $\mathrm{Mg}^{2+}$ (Fig. 2B) as well as those with TOC (Fig. 2C). These comparisons were relevant, as they pointed to the primary factors associated with the elongation of the main branch of the melon, especially in treatments with $C G$ and $\mathrm{BH}$. In the case of $\mathrm{P}$, acidic soil conditions could justify it's low availability for plants. Moreover as biochar contributed to increase $\mathrm{P}$ content along with $\mathrm{pH}$. It could be seen as a natural source of this element, improving plant efficiency in the use of organic and inorganic $P$ fertilizers (Muhammad et al., 2017). At the same time biochar also contributed to increase the availability of $\mathrm{Mg}^{2+}, \mathrm{Ca}^{2+}$, and $\mathrm{K}^{+}$with a raising $\mathrm{pH}$ (Bornø et al., 2018), characterizing the first relation between these attributes (Fig. 2C).

The results of this study highlighted the importance of this research which points out promising alternatives management to improve plant development and soil chemical, microbiological, and enzymatic attributes. In the present study, T. aureoviride isolates demonstrated high versatility both in plant development and in the promotion of enzymatic activity, thus indicating that this fungus becomes a strong candidate for alternative organic input and application in the field using biochar as a route of inoculation.
Materials and Methods

\section{Plant materials}

For this experiment we used the melon hybrid 'BRS Araguaia' that is well appreciated on local market and suitable to exportation for its excellent quality. Three seeds were deposited in each cell and after seven days thinning took place, and only the most vigorous plant was kept and grown at an average room temperature of 28 ㅇ. Trays received daily irrigation, keeping moisture in the range of soil field capacity.

\section{Experiment}

The agronomical experimentation consisted of testing the effect of three types of biochar (BH, CG, and $\mathrm{CH}$ ) with or without inoculation of $T$. aureoviride URM 5158. We used industrial bean husk residues (BH), coffee grounds (CG), and coffee husks $(\mathrm{CH})$ to produce different types of biochar. This biomass was charred for $12 \mathrm{~h}$ under limited oxygen conditions in a slow pyrolysis process in which the temperature reached $530^{\circ} \mathrm{C}$ in a metallic kiln, and they were sieved using a 2-mm sieve. The chemical analysis and specific surface area (SSA) measurements of the different types of biochar can be found in (Lima et al., 2018)

The choice of $T$. aureoviride URM 5158 fungus was based on its physiological and functional versatility mentioned in previous studies (Silva et al., 2016) and was obtained from the Micoteca URM Collection of the Mycology Department of the Biological Sciences Center of the Federal University of Pernambuco (https://www.ufpe.br/micoteca/). The fungus conidia was reactivated through three successive subcultures in an Erlenmeyer flask containing $50 \mathrm{ml}$ of potato dextrose agar (PDA) liquid medium, grown at $26 \pm 2^{\circ} \mathrm{C}$ for eight days. Each treatment with $T$. aureoviride was sprayed with $100 \mathrm{ml}\left(1 \times 10^{6}\right.$ conidia per $\left.\mathrm{ml}\right)$ applied to each type of biochar. The different sources of biochar and T. aureoviride were mixed and homogenized to the soil before planting.

The experiment was conducted at the Federal Rural University of Pernambuco (UFRPE) in Garanhuns in Brazil. The soil used was topsoil (0-20 cm layer) collected in a patch of natural forest area in São João, Brazil $\left(08^{\circ} 48^{\prime} 34.2^{\prime \prime} \mathrm{S}, 36^{\circ}\right.$ $24^{\prime} 29.3^{\prime \prime} \mathrm{W}$ ) at an elevation of $705 \mathrm{~m}$ AMSL. The soil is a typical Entisol with almost $90 \%$ sand and less than $5 \%$ clay and with low cation exchange capacity (CEC) and SSA. The chemical attributes of soil and biochar before the experiment are shown in Lima et al. (2018). This soil was previously treated with formulated fertilizer NPK $(6: 24: 12)$ to prevent variations related to plant nutritional deficits.

Biochar was added at a rate of $32 \mathrm{t} \mathrm{ha}^{-1}$ in the first $20 \mathrm{~cm}$ of soil. The experimental design was completely randomized in a double factorial scheme with additional treatment $(3 \times 2+$ 1). The first factor represented the three types of biochar ( $\mathrm{CG}, \mathrm{CH}$, and $\mathrm{BH}$ ), while the second considered the inoculation $(\mathrm{T}+)$ and absence ( $\mathrm{T}-\mathrm{)}$ of $T$. aureoviride on these substrates. The additional treatment represented absolute control, without biochar nor T. aureoviride.

Then, $100 \mathrm{~mL}$ of the $T$. aureoviride suspension (1.46 conidia $\mathrm{mL}^{-1}$ ) with different types of biochar was added to the soil, followed by the planting of three seeds of the hybrid BRS Araguaia melon variety in each pot. After seven days, only 
the most vigorous plant was kept and grown at an average ambient temperature of $28^{\circ} \mathrm{C}$ under daily manual irrigation, maintaining moisture at the range of soil field capacity.

\section{Biometric analyses of melon plants and soil samples}

Melon plants were removed at the end of the experiment (45 days after emergency) to measure the number of leaves $(N L)$, diameter of the plant base (DIAM), root dry biomass $(R D B)$, root fresh biomass $(R F B)$, shoot dry biomass (SDB), shoot fresh biomass (SFB), shoot length (SLEN), root length (RLEN), Chlorophyll a (ChloA), and Chlorophyll b (ChloB).

\section{Soil chemical attributes}

After removal of the plants from the pots, the soil was collected to measure $\mathrm{pH}$ in water (1:2.5) and the content of $\mathrm{P}, \mathrm{Na}^{+}, \mathrm{K}^{+}, \mathrm{Ca}^{2+}, \mathrm{Mg}^{2+}, \mathrm{Al}^{3+}$, and $\mathrm{H}+\mathrm{Al}^{3+}$, according to the methodology of Silva (2009). The inorganic labile $\mathrm{P}, \mathrm{Na}^{+}$, and $\mathrm{K}^{+}$were extracted using Mehlich's solution $1\left(\mathrm{H}_{2} \mathrm{SO}_{4} .0125\right.$ mol $\mathrm{L}^{-1}+\mathrm{HCl} .05 \mathrm{~mol} \mathrm{~L}^{-1}$ ). The $\mathrm{P}$ quantified by spectrophotometer colorimetry, and the $\mathrm{Na}^{+}$and $\mathrm{K}^{+}$ determined by flame photometry. $\mathrm{Ca}^{2+}, \mathrm{Mg}^{2+}$, and $\mathrm{Al}^{3+}$ were extracted with $\mathrm{KCl} 1.0 \mathrm{~mol} \mathrm{~L}^{-1}$ solution, where the first two were determined by atomic absorption spectrometry (Raij et al., 2001). Potential acidity $\left(\mathrm{H}+\mathrm{Al}^{3+}\right)$ was determined using calcium acetate $\left(\mathrm{Ca}\left(\mathrm{CH}_{3} \mathrm{OO}\right)_{2} \mathrm{H}_{2} \mathrm{O}\right)$ at $\mathrm{pH}$ 7.0. Also, $\mathrm{Al}^{3+}$ was determined by titration with $\mathrm{NaOH} 0.025 \mathrm{~mol} \mathrm{~L}^{-1}$, using bromothymol blue as an indicator. For all extractions, $5.0 \mathrm{~g}$ of soil for $50 \mathrm{~mL}$ of extractive solution (relation 1:10) was used.

Total organic carbon content (TOC) was obtained using the C oxidation method in the wet form with potassium dichromate followed by determination of remaining $\mathrm{Cr}_{2} \mathrm{O}_{7}{ }^{2-}$ by titration with ammonium iron (II) sulfate (Yeomans and Bremner 1988).

\section{Soil microbial attributes}

The microbial biomass carbon (MBC) was determined by irradiation method (Mendonça and Matos 2005), with the extraction carried out by the addition of $80 \mathrm{~mL}$ of $\mathrm{K}_{2} \mathrm{SO}_{4} 0.5$ $\mathrm{M}$ to each $20 \mathrm{~g}$ of soil (Tate et al., 1988). The $\mathrm{C}$ content was determined by colorimetry (Bartlett and Ross, 1988).

The evolution of $\mathrm{CO}_{2}$ released by microbial respiration was measured for calculation of soil basal respiration and soil metabolic quotient $\left(q \mathrm{CO}_{2}\right)$ by the alkaline adsorption method. For this purpose, at the end of the experiment, the soil was maintained at $60 \%$ of field capacity based on gravimetry (Anderson and Domsch, 1985). Then, $30 \mathrm{~g}$ of each sample were hermetically sealed in containers to capture $\mathrm{CO}_{2}$ with $10 \mathrm{~mL}$ of $\mathrm{NaOH} .5 \mathrm{M}$ solution. After $72 \mathrm{~h}, 2$ $\mathrm{mL}$ of $\mathrm{BaCl} 10 \%(\mathrm{~m} / \mathrm{v})$ solution was added for total precipitation of $\mathrm{CO}_{2}$, followed by two drops of phenolphthalein diluted in $100 \mathrm{ml}$ of ethyl alcohol 95\% (v/v) the determinations being carried out by titration with $\mathrm{HCl}$ $0.25 \mathrm{M}$.

\section{Soil enzymatic activities}

We determined the enzymatic soil activities by estimating the gene expression of the main processes related to acid (P.Aci) and alkaline phosphatases (P.Alk) (E.C. 3.1.3), $\beta$ glucosidase (Beta) (E.C. 3.2.1.21), and the urease (Ure) (E.C. 3.5.1.5) according to the colorimetric analysis of the products released by the samples subjected to incubation in an adequate substrate (Sigma-Aldrich). The activities of P.Aci and P.Alk were estimated according to the methodology of Eivazi and Tabatabai (1977). Beta was estimated by the methodology of Eivazi and Tabatabai (1988), and Ure was estimated using the method by Kandeler and Gerber (1988). The absorbance of the products was measured by spectrophotometer (Libra S22, Biochrom, Cambridge, UK).

\section{Statistical analyses}

Statistical and multivariate analyses were conducted using the R language platform $(v .3 .4 .3,2017)$ based on the data of the biometric attributes of the plants, chemicals, and enzymatic activities of the soils. Multivariate exploratory analyzes, including non-metric multidimensional scaling (nMDS), analysis of similarity (ANOSIM), heatmaps, and Mantel tests were based on the tools of the vegan and heatmaply libraries. After adjusting the models and removing the outliers, the means, standard deviations, and variation coefficients were calculated using the doBy library. Homogeneity tests, analysis of variances (ANOVA), and comparisons between averages were done with the balanced data, according to the tools contained in the stats, AxpDes, multicomp, and agricolae libraries.

\section{Conclusions}

Biochar from coffee and bean residues inoculated with $T$. aureoviride and applied to sandy soil are efficient in the initial growth of melon plants in increasing the chemical, microbial, and enzymatic activities of the soil. However, melon plants responded more to the source of biochar than to the $T$. aureoviride inoculation, possibly due to the short growth time of melon. Therefore, it is necessary to perform further studies with more time and more cycles of the crop to verify whether the biochar inoculated with Trichoderma and applied to the soil can promote higher plant production.

\section{Acknowledgments}

We thank fellowships and grants from CNPq (313174/20180; 426497/2018-0; 307335/2017-8; ONDACBC: 465764/2014-2 and NEXUS: 441305/2017-2), and FACEPE (APQ-0223-5.01/15; APQ-0419-5.01/15; APQ-0431-5.01/17; APQ-0498-3.07/17). This study was financed in part by the "Coordenação de Aperfeiçoamento de Pessoal de Nível Superior - Brasil (CAPES)" [Finance Code 001].

\section{References}

Adetunji AT, Lewu FB, Mulidzi R, Ncube B (2017) The biological activities of $\beta$-glucosidase, phosphatase and urease as soil quality indicators: a review. J Soil Sci Plant Nut. 17:794-807.

Anyanwu IN, Alo MN, Onyekwere AM, Crosse JD, Nworie O, Chamba, EB (2018) Influence of biochar aged in acidic soil on ecosystem engineers and two tropical agricultural plants. Ecotox Environ Safe. 153:116-126.

Anderson TH, Domsch KH (1985) Determination of ecophysiological maintenance carbon requirements of soil microorganisms in a dormant state. Biol Fert Soils. 1:81-89.

Bartlett RJ, Ross DS (1988) Colorimetric determination of oxidizable carbon in acid soil solutions. Soil Sci Soc Am J. 53:191-192. 
Bornø ML, Müller-Stöver DS, Liu F (2018) Contrasting effects of biochar on phosphorus dynamics and bioavailability in different soil types. Sci Total Environ. 627:963-974.

Buss W, Shepherd JG, Heal KV, Mašek, O (2018) Spatial and temporal microscale $\mathrm{pH}$ change at the soil-biochar interface. Geoderma. 331:50-52.

Deus JAL, Soares I, Neves JCL, Medeiros JF, Miranda FR (2015) Fertilizer recommendation system for melon based on nutritional balance. Rev Bras Cienc Solo. 39:498-511.

Eivazi F, Tabatabai MA (1977) Phosphatases in soils. Soil Biol Biochem. 9:167-172.

Eivazi F, Tabatabai MA (1988) Glucosidases and galactosidases in soils. Soil Biol Biochem. 20:601-606.

Galletti S, Fornasier F, Cianchetta S, Lazzeri L (2015) Soil incorporation of brassica materials and seed treatment with Trichoderma harzianum: effects on melon growth and soil microbial activity. Ind Crop Prod. 75:73-78.

Gul S, Whalen JK, Thomas BW, Sachdeva V, Deng H (2015) Physico-chemical properties and microbial responses in biochar-amended soils: mechanisms and future directions. Agr Ecosyst Environ. 206:46-59.

Kandeler E, Gerber H (1988) Short-term assay of soil urease activity using colorimetric determination of ammonium. Biol Fert Soils. 6:68-72.

Lima JRS, de Moraes Silva W, de Medeiros EV, Duda GP, Corrêa MM, Martins Filho AP, Hammecker C (2018) Effect of biochar on physicochemical properties of a sandy soil and maize growth in a greenhouse experiment. Geoderma. 319:14-23.

Mallek-Ayadi S, Bahloul N, Kechaou N (2018) Chemical composition and bioactive compounds of Cucumis melo $\mathrm{L}$. seeds: Potential source for new trends of plant oils. Process Saf Environ. 113:68-77.

Medeiros EV, Moraes MCS, Costa DP, Duda GP, Silva JS, Oliveira JB, Lima JRS, Hammecker, C (2019) A new approach of biochar as a route of Trichoderma aureoviride inoculation: Effect on soil quality and watermelon growth. Catena. (In press).

Mendonça ES, Matos ES (2005) Matéria orgânica do solo: Métodos de análises, 2nd ed. UFV, Viçosa.

Mendoza-Mendoza A, Zaid R, Lawry R, Hermosa R, Monte E, Horwitz BA, Mukherjee PK (2018) Molecular dialogues between Trichoderma and roots: Role of the fungal secretome. Fungal Biol Rev. 32:62-85

Mouginot C, Kawamura R, Matulich KL, Berlemont R, Allison SD, Amend AS, Martiny, AC (2014) Elemental stoichiometry of Fungi and Bacteria strains from grassland leaf litter. Soil Biol Biochem. 76:278-285.

Muhammad A, Ilyas M, Riaz M, Ali K, Shah K, UI Haq I, Fahad $S$ (2017) Biochar improves phosphorus use efficiency of organic-inorganic fertilizers, maize-wheat productivity and soil quality in a low fertility alkaline soil. Field Crop Res 214:25-37.

Paneque M, De La Rosa JM, Franco-Navarro JD, ColmeneroFlores JM, Knicker H (2016) Effect of biochar amendment on morphology, productivity, and water relations of sunflower plants under non-irrigation conditions. Catena. 147:280-287.
Prasad M, Tzortzakis N, McDaniel N (2018) Chemical characterization of biochar and assessment of the nutrient dynamics by means of preliminary plant growth tests. J Environ Manage 216:89-95.

Raij BV, Andrade JC, Cantarella H, Quaggio JA (2001) Análise química para avaliação da fertilidade de solos tropicais. Instituto Agronômico, Campinas.

Sheng Y, Zhu L (2018) Biochar alters microbial community and carbon sequestration potential across different soil pH. Sci Total Environ. 622:1391-1399.

Silva FC (2009) Manual de análises químicas de solos, plantas e fertilizantes. 2nd ed. Embrapa, Brasília.

Silva JAT, Medeiros EV, Silva JM, Tenório DA, Moreira KA, Nascimento DS, Souza-Motta C (2016) Trichoderma aureoviride URM 5158 and Trichoderma hamatum URM 6656 are biocontrol agents that act against cassava root rot through different mechanisms. J Phytopathol. 164:1003-1011.

Song D, Tang J, Xi X, Zhang S, Liang G, Zhou W, Wang X (2018) Responses of soil nutrients and microbial activities to additions of maize straw biochar and chemical fertilization in a calcareous soil. Eur J Soil Biol. 84:1-10.

Strahsburger E, de Lacey AML, Marotti I, DiGioia D, Biavati B, Dinelli $G$ (2017) In vivo assay to identify bacteria with $\beta$ glucosidase activity. Electron J Biotechn. 30:83-87.

Swain $\mathrm{H}$, Adak $\mathrm{T}$, Mukherjee AK, Mukherjee PK, Bhattacharyya P, Behera S, Bagchi, T B, Patro R, Shasmita, A, Bag MK, Dangar TK, Lenka S, Jena M (2018) Novel Trichoderma strains isolated from tree barks as potential biocontrol agent and biofertilizers for direct seeded rice. Microbiol Res. 214:83-90.

Tate KR, Ross DJ, Feltham CW (1988) A direct extraction method to estimate soil microbial C: effects of experimental variables and some different calibration procedures. Soil Biol Biochem. 20:329-335.

Teutscherova N, Lojka B, Houška J, Masaguer A, Benito M, Vazquez E (2018) Application of holm oak biochar alters dynamics of enzymatic and microbial activity in two contrasting Mediterranean soils. Eur J Soil Biol. 88:15-26.

Tripti K, Adarsh U, Zeba K, Vipin A (2017) Biochar and flyash inoculated with plant growth promoting Rhizobacteria act as potential biofertilizer for luxuriant growth and yield of tomato plant. J Environ Manage. 190:20-27.

Weber K, Quicker P (2018) Properties of biochar. Fuel 217:240-261.

Wu D, Senbayram M, Zang H, Ugurla, F, Aydemir S, Brüggemann N, Blagodatskaya E (2018) Effect of biochar origin and soil $\mathrm{pH}$ on greenhouse gas emissions from sandy and clay soils. Appl Soil Ecol. 129:121-127

Yang Y, Sun K, Han L, Jin J, Sun H, Yang Y, Xing B (2018) Effect of minerals on the stability of biochar. Chemosphere. 204:310-317.

Yeomans JC, Bremner JM (1988) A rapid and precise method for the routine determination of organic carbon in soil. Commun Soil Sci Plan. 19:1467-1476 